\title{
Relationship between different livestock managements and stress response in dairy ewes
}

\author{
Vincenzo Carcangiu ${ }^{1}$, Francesca Arfuso ${ }^{2}$, Sebastiano Luridiana ${ }^{1}$, Claudia Giannetto ${ }^{1}$, Maria Rizzo ${ }^{2}$, \\ Pier Paolo Bini ${ }^{1}$, and Giuseppe Piccione ${ }^{2}$ \\ ${ }^{1}$ Department of Veterinary Medicine, University of Sassari, Via Vienna 2, 07100, Sassari, Italy \\ ${ }^{2}$ Department of Veterinary Sciences, University of Messina, \\ Polo Universitario dell' Annunziata, 98168, Messina, Italy
}

Correspondence: Giuseppe Piccione (giuseppe.piccione@unime.it)

Received: 28 July 2017 - Revised: 1 December 2017 - Accepted: 18 December 2017 - Published: 22 January 2018

\begin{abstract}
The gradual diffusion of intensive and semi-intensive production systems, especially in dairy sheep breeds, has led to the growing concern of consumers about the life conditions of farmed animals. Space allowance and structures of sheep houses are described as the main potential sources of discomfort for housed flocks, together with inappropriate milking procedures and human-animal interactions. The aim of the present study was to evaluate whether the structure relative to milking room could represent a stressor in Sarda dairy ewes. Animals were divided into two groups according to their farm of origin. Group A $(n=40)$ was from a farm whose milking room was an old warehouse with a waiting area limited and located outdoors and at a different level with respect to the milking room. The passageway of the entrance in the milking room was narrow and perpendicular to the milking positioning so the animal must bend $90^{\circ}$ to enter in the room. Group B $(n=40)$ was from a farm whose milking room was wide and modern with a large waiting area located at the same level. From all animals blood samples were collected at $T_{0}$ ( $2 \mathrm{~h}$ before milking procedure at 06:00), at $T_{1}$ (immediately after the animals entered the milking room, about 08:00) and at $T_{2}$ (after milking procedure). In addition plasma cortisol and glucose values were evaluated. Statistical analysis showed significant effect of milking room $(P<0.001)$ and of sampling time $(P<0.05)$ on cortisol and glucose levels. The results obtained in the present study suggest that, in addition to milking, the characteristics of the room where this procedure occurs represent stressful stimuli that could influence negatively the productivity and welfare of dairy ewes.
\end{abstract}

\section{Introduction}

Animal welfare has contributed to a better understanding of how animals perceive their social and physical environment, their motivations, and the physiological and behavioural needs, enabling the design of environments to better satisfy these needs (Webster, 2005). Several studies have addressed the definition of animal welfare and the most suitable indicators to its evaluation, particularly, in the production under intensive conditions, where animals frequently face situations implying behavioural, physiological and physical stress including restraint, handling or novelty, hunger, thirst, fatigue, injury or thermal extremes (Mason and Mendl, 1993; Blokhuis et al., 2003; Mason and Latham, 2004). Stress can be defined as a physiological response elicited when threat to homeostasis is perceived. In response to stressors, the central nervous system of livestock (and other mammalian species) evokes physiological responses that ultimately result in activation of the hypothalamo-pituitary-adrenocortical (HPA) axis and the sympathoadrenal axis inducing endocrine and metabolic changes (Carcangiu et al., 2008). The responses of these major systems are presumed to have adaptive and homeostatic value during periods of stress. Reducing stress during handling will provide advantages of increasing productivity (Grandin, 1998). The severity of the reaction is governed by a number of factors including individual sensitivity, unfamiliarity to the stimulus and the relative intensity (Grandin, 1997). The stress of handling can be reduced by using well-maintained systems and the development of ap- 
propriate systems should be guided by the requirement to ensure high standards of animal welfare (Goddard et al., 2006). Dairy ewe production systems have traditionally been characterized by the utilization of extensive grazing areas (Boyazoglu and Morand-Fehr, 2001), where spatial restriction may be considered small, or virtually non-existent. Nonetheless, the progressive transition from traditional to modern production systems has led to the use of more intensive husbandry procedures and higher productive efficiency in sheep (Shrestha, 2011). The transition to modern farming systems can impose severe restrictions on the space available for dairy sheep. The use of the milking machine belongs to the modern farming systems and it determines a reduction in the animals handling and, consequently, a decrease in stress (Yardimci et al., 2013). However, the milking rooms show some critical points that can be a source of stress. It has been demonstrated that stress during milking can substantially reduce milk yield through a central inhibition of oxytocin secretion and peripheral action of catecholamines (Rushen et al., 2001). Moreover, the behavioural response of the animal to stress can increase the risk of injury and reduce the efficiency of milking (Rushen et al., 2001). Therefore, it is important to identify and reduce emotional or physical stress of dairy animals during the milking process in order to increase their productivity and to maintain their health status.

In view of such considerations, the aim of the present study was to evaluate whether the structure relative to milking room could represent a stressor in dairy ewe by measuring plasma cortisol and glucose levels before and after milking procedure.

\section{Material and methods}

\subsection{Farm conditions and animals}

A total of 80 Sarda dairy ewes were selected from 2 farms (Farm A and B) of sheep with a total of 200 animals each located in Sardinia (Italy) at the same altitude (529 $\mathrm{m}$ above sea level) and environmental conditions. The farms were different for milking room characteristics. In Farm A the milking room was an old warehouse with a waiting area limited and located outdoors and at a different level with respect to the milking room. The passageway of the entrance in the milking room was narrow and perpendicular to the milking positioning so the animal must bend $90^{\circ}$ to enter in the room. In Farm B the milking room was wide and modern with a large waiting area located at the same level. From both Farm A and Farm B, 40 ewes with a mean body weight of $41.5 \pm 0.5 \mathrm{~kg}$ and age between 2 and 5 years old were selected constituting Group A and Group B, respectively.

All the animals in the study were clinically healthy with no evidence of disease and free from internal and external parasites. Their health status was evaluated based on rectal temperature, heart rate, respiratory rate, appetite, faecal consistency and hematologic profile. Fresh faecal samples were
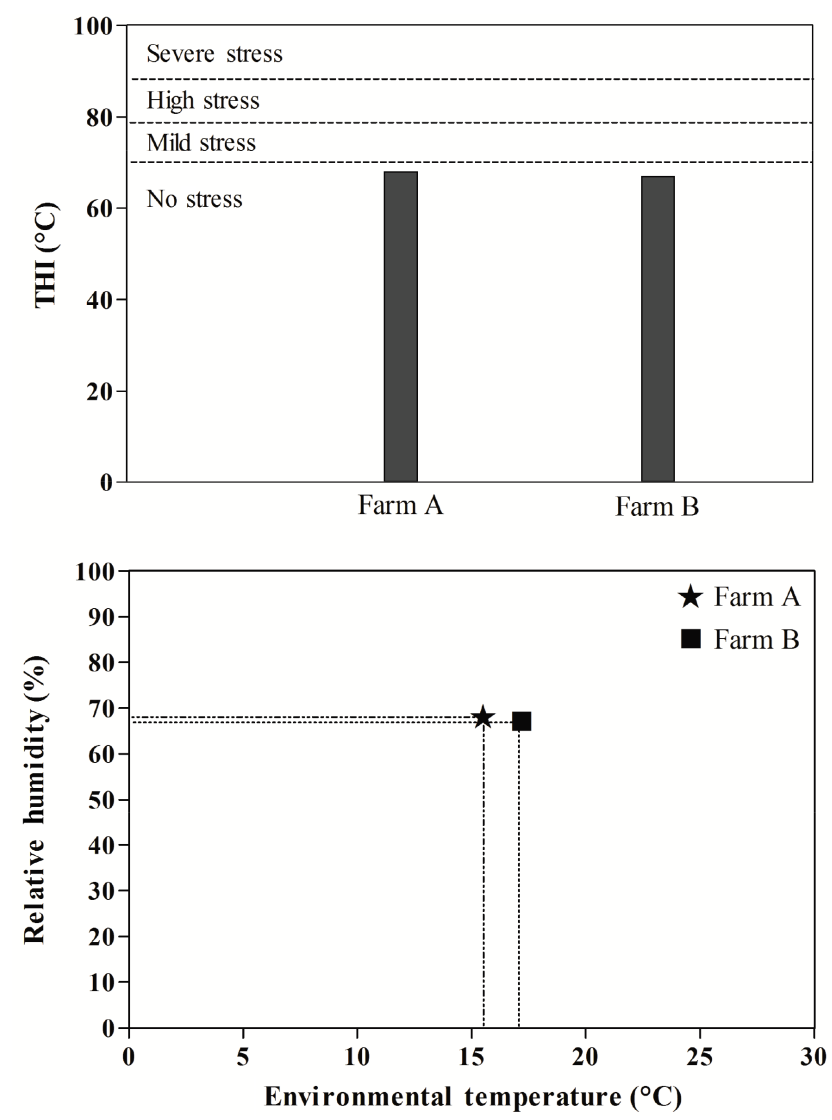

Figure 1. Temperature-humidity index (THI) values calculated for Farm A and Farm B with the respective environmental conditions.

examined according to the McMaster method based on protocols previously described by Maffa (1989). All the animals were kept in two indoor pens under natural photoperiod (sunrise at 05:54, sunset at 19:10 over the study period) and natural environmental temperature. Thermal and hygrometric records were carried out inside the box for the whole study by means of a data logger (Gemini, UK), and they followed the normal spring seasonal pattern for the location. The temperature-humidity index (THI) value, an indicator of thermal comfort, was calculated using the National Weather Service temperature humidity index formula for ruminant species (Potter and Jacobsen, 2000):

THI $\left({ }^{\circ} \mathrm{C}\right)=T^{\circ}$ ambient $+(0.36 \cdot$ point of steam condensation $)+41.5$.

The temperature-humidity index (THI) values calculated for Farm A and Farm B with the respective climatic conditions are reported in Fig. 1.

All ewes were fed with a diet composed of a concentrate mixture which consisted of the following ingredients: oat $12 \%$, faba bean $15 \%$, barley $25 \%$, pea $10 \%$, sugar beet pulp $20 \%$, molasses $5 \%$, and mineral and vitamins supplements $3 \%$. Forage-based diets were alfalfa (Medicago sativa L.) 
hay. About $250 \mathrm{~g}$ per animal of concentrate was distributed twice a day. Water was available ad libitum.

Lambs were weaned 35 days after birth. After weaning all ewes were milked twice daily with the milking machine. The animals were handled every day by the same operator.

All the animals were identified by the number plate of the local sanitary company and by a numbered collar applied to make the recognition of the subjects easier.

\subsection{Blood sampling and laboratory analysis}

From each animal of both farms blood sampling was performed by the same operator after approximately 20 days from the start of milking to ensure the adaptation of ewes to these procedures. Blood was sampled by jugular venipuncture into heparinized tubes (Becton Dickinson, Plymouth, $\mathrm{UK})$ at $T_{0}\left(2 \mathrm{~h}\right.$ before milking procedure at 06:00), at $T_{1}$ (immediately after the animals entered the milking room, about 08:00) and at $T_{2}$ (after the milking procedure).

The milking procedure lasted about $10 \mathrm{~min}$. The blood was immediately centrifuged at $3000 \mathrm{rpm}$ for $20 \mathrm{~min}$ at $4{ }^{\circ} \mathrm{C}$, and the obtained plasma samples were stored at $-20^{\circ} \mathrm{C}$ until analysis. Plasma concentration of cortisol was measured with the Immulite 2000 (Siemens Healthcare Diagnostic, Deer field, IL, USA), which uses a solid-phase competitive enzyme-amplified chemiluminescent immunoassay. Plasma glucose concentration was evaluated using an enzymatic colorimetric method GOD-POD-PAP (Sentinel Chemical, Milan, Italy).

Protocols of animal husbandry and experimentation were reviewed and approved in accordance with the standards recommended by the Guide for the Care and Use of Laboratory Animals and Directive 2010/63/EU for animal experiments.

\subsection{Statistical analysis}

Data, expressed as mean values \pm standard deviation (SD), were tested for normality using the Shapiro-Wilk normality test. All data were normally distributed $(P>0.05)$ and the statistical analysis was performed. Two-way analysis of variance (ANOVA) for repeated measure was applied to assess significant effects of the experimental conditions (milking room and time) on plasma cortisol and glucose levels. When significant differences were found, Bonferroni's post hoc comparison was applied. $P$ values $<0.05$ were considered statistically significant. Statistical analysis was performed using the STATISTICA software package (STATISTICA 7 Stat Software Inc., Tulsa, Oklahoma).

\section{Results}

Statistical analysis showed a significant effect of milking room $(P<0.001)$ on plasma cortisol and glucose levels. As shown in Fig. 2, Group A showed higher cortisol and glucose concentration with respect to Group B at $T_{1}$ and $T_{2}$.
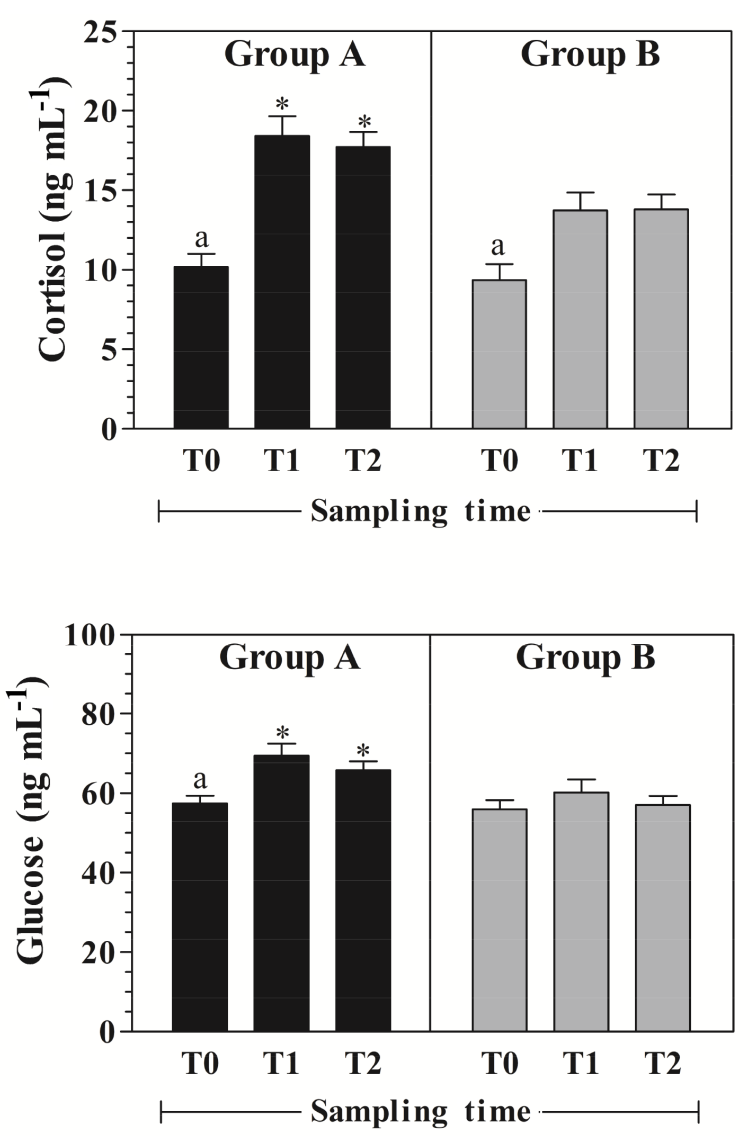

Significant effect of milking room: * vs. Group B at T1 and T2 $(\mathrm{P}<0.001)$ Significant effect of sampling time: ${ }^{\mathrm{a}} \mathrm{vs.} \mathrm{T} 1$ and $\mathrm{T} 2(\mathrm{P}<0.05)$

Figure 2. Mean values \pm standard deviation $( \pm S D)$ of plasma cortisol and glucose obtained from dairy ewes (Group A and Group B) at $T_{0}$ ( $2 \mathrm{~h}$ before milking procedure at 06:00), at $T_{1}$ (immediately after the animals entered the milking room, about 08:00) and at $T_{2}$ (after milking procedure).

A significant effect of sampling time was found on studied parameters. In particular, higher plasma cortisol values were found at $T_{1}$ and $T_{2}$ with respect to $T_{0}$ in Groups A and B $(P<0.05)$. Plasma glucose showed increased values $(P<$ 0.05 ) at $T_{1}$ and $T_{2}$ with respect to $T_{0}$ in Group A (Fig. 2).

\section{Discussion}

Domestic animals are routinely exposed to a variety of anthropogenic stressors. Milking management represents a critical point in sheep farm. The time animals need to adapt to machine milking, pre-parturition training to milking parlour, and type of milking (i.e. hand or machine milking), can markedly affect the welfare, health and production performance of dairy sheep. Although the use of the milking machine belonging to the modern farming systems determines 
a reduction in the animal handling and, consequently, a decrease in stress (Yardimci et al., 2013), the milking rooms show some critical points that can be a source of stress. Under stressful stimuli the body must find a new dynamic equilibrium, and this requires several adaptive body responses.

It is well established that season, ambient temperature, as well as THI, and the other climatic conditions affect physiological, biochemical and hematological parameters in sheep (Piccione et al., 2011, 2012). THI values of 70 or less are considered comfortable, 75-78 stressful, and values greater than 78 cause extreme distress (Di Grigoli et al., 2009). The two farms considered in the present study showed very similar values of ambient temperature, relative humidity and THI. THI calculated for Farm A and Farm B was 61.78 and $63.72{ }^{\circ} \mathrm{C}$, respectively, and were within the thermoneutral zone reported for the sheep (Nikitchenco et al., 1998; Di Grigoli et al., 2009). This excludes the influence of climatic conditions on studied parameters.

The results obtained in this study seem to suggest that milking room characteristics influence welfare of dairy ewes. Animals belonging to Farm A showed statistically significant higher plasma cortisol and glucose levels in comparison to animals of Farm B immediately after the animals entered the milking room $\left(T_{1}\right)$ and after the milking procedure $\left(T_{2}\right)$. Contrary to Farm B, whose milking room was wide and modern with a large waiting area located at the same level, milking room of Farm A was an old warehouse with a limited waiting area. Moreover, the animals of Farm A are forced in small bunches into tight spaces before entering the milking position, and they had to curve a rigid $90^{\circ}$ to move to the milking location. All these factors could represent stress stimuli for dairy animals. Effectively, change in the basal level of cortisol in response to short-term stress can be considered an important indicator of animal welfare. Several studies carried out on sheep showed that some management activities, including isolation, artificial milk feeding and weaning, represent stressful conditions leading to an increase in the blood cortisol levels (Carcangiu et al., 2008; Napolitano et al., 1995, 2003; Orgeur et al., 1998). Animals of both considered groups showed statistically significant higher cortisol values at $T_{1}$ and $T_{2}$ with respect to $T_{0}$ probably due to milking procedures. Effectively, it has been suggested that machine milking is associated with a peak in plasma cortisol in lactating animals (Ndibualonji et al., 1995). Such phenomena may be assimilated to suckling stimuli, which have been reported to induce the release of corticosteroids in rats (Voogt et al., 1969). It has been suggested that both suckling (Voogt et al., 1969) and milking (Koprowski and Tucker, 1973) stimulate nerve endings in the nipples, which send impulses to the brain via the spinal cord, resulting in the sequential release of ACTH-releasing factor, pituitary ACTH, and finally adrenal corticosteroids. The animal response to stress factors is mainly centred in the activation of the sympathetic system and the hypothalamic-hypophysis-adrenal axis through catecholamine and glucocorticoid production
(Miller and O'Callaghan, 2002). These hormones render the animals alert, thus giving them the ability to react to environmental stimuli, in order to preserve organic homeostasis (Herman and Cullinan, 1997). Glucocorticoids and catecholamines also cause a rise in glycaemia, starting from glucidic and non-glucidic substrates such as proteins and an increase of non-esterified fatty acid (NEFA), derived from lipid mobilization (McMahon et al., 1988). Taken together, these effects produce a greater availability of energy for the brain and muscles, and thereby a more efficient behavioural response to stress. Plasma glucose concentration rose in both groups at $T_{1}$ and $T_{2}$ with respect to $T_{0}$, although this increase was statistically significant in Group A, only. The rise in glucose levels is directly proportional to cortisol levels and must therefore be attributed to the hyperglycaemic effect of this hormone, to which we may add an increased glucose production by the liver, due to stimulation of sympatheticadrenergic activity (Ali et al., 2001).

\section{Conclusion}

The results obtained in the present study suggest that, in addition to milking, the characteristics of the room where this procedure occurs represent stressful stimuli that could influence negatively productivity and welfare of dairy ewes. Therefore, the breeders should pay particular attention to the structures of their farms in order to make the functional spaces less stressful for animals.

Data availability. Data are available from the corresponding author upon request.

Author contributions. All authors have made substantial contributions to each step of experimental procedure and manuscript preparation: VC contributed to the experiment design and prepared the manuscript. FA performed the laboratory analysis. SL and CG performed the sampling. RM and PPB analysed the data. GP supervised all stages of the experimental study.

Competing interests. The authors declare that they have no conflict of interest.

Edited by: Steffen Maak

Reviewed by: two anonymous referees

\section{References}

Ali, B. H., Al-Qarawi, A. A., Mousa, H. M., and Mohammed, S. M.: Tyrosine ameliorates some of the chemical, biochemical and haematological effects of acute stress associated with transportation of desert sheep, Vet. Res. Commun., 25, 503-510, 2001. 
Blokhuis, H. J., Jones, R. B., Geers, R., Miele, M., and Veissier, I.: Measur-ing and monitoring animal welfare: transparency in the food productquality chain, Anim. Welfare, 12, 445-455, 2003.

Boyazoglu, J. and Morand-Fehr, P.: Mediterranean dairy sheep and goatproducts and their quality: a critical review, Small Rumin. Res., 40, 1-11, 2001.

Carcangiu, V., Vacca, G. M., Parmeggiani, A., Mura, M. C., Pazzola, M., Dettori, M. L., and Bini, P. P.: The effect of shearing procedures on blood levels of growth hormone, cortisol and other stress haematochemical parameters in Sarda sheep, Animal, 2, 606-612, 2008.

Di Grigoli, A., Todaro, M., Di Miceli, G., Alicata, M. L., Cascone, G., and Bonanno, A.: Milk production and physiological traits of ewes and goats housed indoor or grazing at different daily timing in summer, Ital. J. Anim. Sci., 8, 616-618, 2009.

Goddard, P., Waterhouse, T., Dwyer, C., and Stott, A.: The perception of the welfare of sheep in extensive systems, Small Rumin. Res., 62, 215-225, 2006.

Grandin, T.: Assessment of stress during handling and transport, J. Animal Sci. 75, 249-257, 1997.

Grandin, T.: Review: reducing handling stress improves both productivity and welfare, Prof. Anim. Sci., 14, 1-10, 1998.

Herman, J. P. and Cullinan, W. E.: Neurocircuitry of stress: central control of the hypothalamo-pituitary-adrenocortical axis, Trends Neurosci., 20, 78-84, 1997.

Koprowski, J. A. and Tucker, H. A.: Bovine serum growth hormone, corticoids and insulin during lactation, Endocrinology, 93, 645$651,1973$.

Maffa: MAFF, Ministery of Agriculture Fisheries and Food, Manual of veterinary laboratory diagnostic techniques, Reference Book No. 418, Her Majesty's Stationery Office, London, 1989.

Mason, G. J. and Latham, N. R.: Can't stop, won't stop: is stereotypy a reliable animal welfare indicator?, Anim. Welfare, 13, 5769, 2004.

Mason, G. J. and Mendl, M.: Why is there no simple way of measuring animal welfare?, Anim. Welfare, 2, 301-319,1993.

McMahon, M., Gerich, J., and Rizza, R.: Effects of glucocorticoids on carbohydrate metabolism, Diabetes Metab. Rev., 4, 17-30, 1988.

Miller, D. B. and O'Callaghan, J. P.: Neuroendocrine aspects of the response to stress, Metabolism, 51, 5-10, 2002.

Napolitano, F., Marino, V., De Rosa, G, Capparelli, R., and Bordi, A.: Influence of artificial rearing on behavioral and immune response of lambs, Appl. Anim. Behav. Sci., 45, 245-253, 1995.
Napolitano, F., Annicchiarico, G., Caroprese, M., De Rosa, G., Taibi, L., and Sevi, A.: Lambs prevented from suckling their mothers display behavioral, immune and endocrine disturbances, Physiol. Behav., 78, 81-89, 2003.

Ndibualonji, B. B., Dehareng, D., Van Eenaeme, C., and Godeau, J. M.: Response of milk yield, plasma cortisol, amino acids, urea and glucose to a single low-dose administration of adrenocorticotrophic hormone in lactating cows, Vet. Res. BioMed Central, 26, 32-42, 1995.

Nikitchenko, I. N., Plyaschenko, S. I., and Zenkov, A. C.: Stresses and productivity of farm animals, Urajai Publishing House, Minsk, 200, 1998.

Orgeur, P., Mavric, N., Yvore, P., Bernard, S., Nowak, R., Schaal, B., and Levy, F.: Artificial weaning in sheep: consequences on behavioural, hormonal and immunopathological indicators of welfare, Appl. Anim. Behav. Sci., 58, 87-103, 1998.

Piccione, G., Messina, V., Giannetto, C., Casella, S., Assenza, A., and Fazio, F.: Seasonal variations of the serum proteins in sheep and goats, Arch. Tierz., 54, 399-405, 2011.

Piccione, G., Messina, V., Vazzana, I., Dara, S., Giannetto, C., and Assenza, A.: Seasonal variations of some serum electrolyte concentrations in sheep and goats, Comp. Clin. Pathol., 21, 911-915, 2012.

Potter, C. F. and Jacobsen, K. L.: La riduzione dello stress da calore in un allevamento di bovine da latte del nord-est degli USA, Large Anim. Rev., 6, 35-41, 2000.

Rushen, J., Munksgaard, L., Marnet, P. G., and DePassillé, A. M.: uman contact and the effects of acute stress on cows at milking, Appl. Anim. Behav. Sci., 73, 1-14, 2001.

Shrestha, J. N. B.: Dairy farm management systems|sheep, in: Encyclopedia of Dairy Sciences, edited by: Fuquay, J. W., Fox, P F., and McSweeney, P. L. H., 2nd Edition, Four-Volume set, Academic Press, San Diego, USA, 67-76, 2011.

Voogt, J. L., Sar, M., and Meites, J.: Influence of cycling, pregnancy, labor, and suckling on corticosterone-ACTH levels, Am. J. Physiol., 216, 655-658, 1969.

Webster, J.: The assessment and implementation of animal welfare: theory into practice, Rev. Sci. Tech., 24, 723-734, 2005.

Yardimci, M., Sahin, E. H., Cetingul, I. S., Bayram, I., Aslan, R., and Sengor, E.: Stress responses to comparative handling procedures in sheep, Animal, 7, 143-150, 2013. 